\title{
Graves' hyperthyroidism in pregnancy: a clinical review
}

\author{
Caroline T. Nguyen ${ }^{1 *}$, Elizabeth B. Sasso ${ }^{2}$, Lorayne Barton ${ }^{3}$ and Jorge H. Mestman ${ }^{4}$
}

\begin{abstract}
Background: Graves' hyperthyroidism affects $0.2 \%$ of pregnant women. Establishing the correct diagnosis and effectively managing Graves' hyperthyroidism in pregnancy remains a challenge for physicians.

Main: The goal of this paper is to review the diagnosis and management of Graves' hyperthyroidism in pregnancy. The paper will discuss preconception counseling, etiologies of hyperthyroidism, thyroid function testing, pregnancyrelated complications, maternal management, including thyroid storm, anti-thyroid drugs and the complications for mother and fetus, fetal and neonatal thyroid function, neonatal management, and maternal post-partum management.

Conclusion: Establishing the diagnosis of Graves' hyperthyroidism early, maintaining euthyroidism, and achieving a serum total T4 in the upper limit of normal throughout pregnancy is key to reducing the risk of maternal, fetal, and newborn complications. The key to a successful pregnancy begins with preconception counseling.
\end{abstract}

Keywords: Hyperthyroidism, Pregnancy, Antithyroid drugs, Methimazole, Propylthiouracil, TRAb, Neonatal hyperthyroidism, Thyroid storm

\section{Background}

Graves' Hyperthyroidism (GH) is an autoimmune condition caused by antibodies stimulating the thyroid stimulating hormone receptor (TSHR). GH affects $0.2 \%$ of pregnant women [1]. Establishing the correct diagnosis and effectively managing $\mathrm{GH}$ in pregnancy is challenging; pregnancy alters thyroid physiology and laboratory testing, antithyroid drugs (ATDs) are associated with teratogenicity, and maternal, fetal, and newborn complications are directly related to control of $\mathrm{GH}$ and in a few cases to the levels of serum maternal thyroid-stimulating immunoglobulin (TSI) [2]. Fetal and neonatal hyperthyroidism occurs in $1 \%$ to $5 \%$ of women with active or a past history of GH and is associated with increased fetal/neonatal morbidity and mortality if not diagnosed and treated [3]. All women of reproductive age with GH or past history of GH should receive preconception counseling.

* Correspondence: Caroline.Nguyen@med.usc.edu

${ }^{1}$ Division of Endocrinology, Diabetes, \& Metabolism, Department of Medicine, Keck School of Medicine, University of Southern California, 1540 Alcazar

Street, CHP 204, Los Angeles, Ca 90033, USA

Full list of author information is available at the end of the article

\section{Preconception counseling}

Counseling should take into consideration the woman's desired timeline to conception and include a discussion of the risks and benefits of all treatment options (medical therapy, 131-I radioactive iodine ablation (RAIA), and surgery). Women with GH should be advised to postpone conception and use contraception until GH is controlled. Women with difficult to control GH on high doses of ATD should consider definitive therapy (RAIA or surgery) prior to conception.

In women considering RAIA, a pregnancy test should be done beforehand and conception should be delayed for 6 months until the woman is euthyroid on levothyroxine replacement therapy. TSH Receptor Antibodies (TRAb), measurable in $95 \%$ of patients with $\mathrm{GH}$, may increase and stay elevated for months to years after RAIA therapy $[4,5]$. Persistently elevated TRAb levels during pregnancy are prognostic of fetal thyroid dysfunction [6]. Consequently, women with very elevated TRAb levels prior to conception may be better candidates for thyroidectomy. After surgery, TRAb levels decrease and normalize within months to one year $[4,5]$.

In women who continue with ATD treatment, methimazole (MMI) is generally preferred to propylthiouracil (PTU) because MMI is dosed once daily and PTU has 
an association with hepatotoxicity. However, PTU is recommended for the first trimester of pregnancy because its teratogenic effects are considered less severe than those of MMI. Switching from MMI to PTU in anticipation of conception should be considered. Alternatively, women may switch to PTU once pregnant.

Patients taking ATDs should use contraception and be counseled to pay close attention to menstrual cycles. A pregnancy test should be done immediately if there is a missed period. The risk of birth defects from ATDs is greatest during weeks 6-10 [7].

\section{Etiologies of hyperthyroidism}

While the etiologies of hyperthyroidism are extensive (Table 1), GH and gestational transient thyrotoxicosis (GTT) account for the majority of hyperthyroidism in pregnancy. Distinguishing between GTT and GH is important because GTT is a transient, mild hyperthyroidism that does not require treatment with ATD and is not associated with adverse pregnancy outcomes [8].

\section{Gestational transient thyrotoxicosis (GTT)}

GTT affects $1-5 \%$ of pregnant women early in pregnancy and is not due to intrinsic thyroid disease [9]. As in GH, patients with GTT may present with palpitations, anxiety,

Table 1 Causes of Hyperthyroidism in Pregnancy [33]

Thyroid Disease
Graves' disease
Chronic thyroiditis
Painless thyroiditis
Subacute thyroiditis
Toxic adenoma
Multinodular goiter
Non-autoimmune hyperthyroidism
Gestational transient thyrotoxicosis
Multiple gestations
Trophoblastic disease
Hyperplacentosis
Hyperreactio luteinalis
TSH receptor mutation
TSH-producing pituitary adenoma
latrogenic
Excessive levothyroxine (LT4) intake
Overtreatment
Factitious
Drugs
lodine

tremors, and heat intolerance. A severe form of GTT is hyperemesis gravidarum, which is characterized by significant nausea, vomiting, and weight loss of up to $5 \mathrm{~kg}$. These symptoms along with negative TRAb and the absence of Graves ophthalmopathy, goiter, and prior history of GH favor the diagnosis of GTT. The clinical course is closely correlated with hCG levels, which begin to rise at week 7 of gestation. Symptoms spontaneously resolve as serum concentration of hCG decreases between weeks 14 and $20[10]$.

Women with twin pregnancies, another frequent cause of GTT, have higher levels of human chorionic gonadotropin (hCG) for a more prolonged period of time and consequently may be more symptomatic [11]. Trophoblastic disease (i.e., hydatidiform moles and choriocarcinoma) are also associated with elevated hCG levels and hyperthyroidism. Biochemically, GTT is characterized by a suppressed thyroid-stimulating hormone (TSH) and mildly elevated free thyroxine (FT4). TRAb are typically absent. TSH levels may continue to be suppressed for weeks after resolution of GTT. In very symptomatic patients a trial of beta-blocker may provide relief. In pregnancy, propranolol is preferred as atenolol has been associated with decreased birth weight $[12,13]$. Women with a prior history of GTT have a higher likelihood of having a repeat episode [9].

\section{Graves' hyperthyroidism (GH)}

As described above, the signs and symptoms of $\mathrm{GH}$ in pregnancy are similar to those of a non-pregnant $\mathrm{GH}$ patient. The diagnosis of $\mathrm{GH}$ should be suspected in a hyperthyroid pregnant woman who 1) was having symptoms prior to pregnancy 2) had a prior diagnosis of hyperthyroidism, and 3) had a previous birth to an infant with thyroid dysfunction.

The small increase in GH incidence and worsening of $\mathrm{GH}$ symptoms described in early pregnancy may be from the stimulation of the thyroid gland by hCG or elevation in TRAb levels during the first trimester [14-16]. As pregnancy progresses, changes in the immunologic response lead to improvement in symptoms. Postpartum, a rebound of the immune system can lead to exacerbation of $\mathrm{GH}$ [17].

\section{Thyroid function tests}

In response to the rising hCG in early pregnancy, TSH concentrations may be below the non-pregnant reference range in up to $10 \%$ of normal pregnant women with $0.5-$ $1 \%$ of women with completely suppressed TSH levels [18].

In the latter half of pregnancy, increased thyroidbinding globulin (TBG) and decreased serum albumin concentration can affect the widely available FT4 automated immunoassays resulting in significant variability 
between assays [19-21]. FT4 concentration also continuously declines throughout pregnancy [21]. Consequently, assay and trimester-specific pregnancy reference ranges are necessary if FT4 is used.

During pregnancy, the total thyroxine (TT4) assay is more consistent between assays. An estrogen-driven increase in TBG leads to the steady rise of TT4 from the first trimester until mid-gestation when the TT4 plateaus. After week 16, the non-pregnancy reference range may be adjusted by a factor of 1.5 and used to assess thyroid status (i.e., $4.5-12.5 \mu \mathrm{g} / \mathrm{dL}$ becomes $6.75-18.75 \mu \mathrm{g} / \mathrm{dL}$ ) [21].

In addition, the FT4 index (FT4I) is a reliable marker of free thyroxine status during pregnancy, correcting TT4 for alterations in TBG $[21,22]$.

Free and total triiodothyronine (FT3/TT3) are rarely useful in the diagnosis and management of $\mathrm{GH}$ in pregnancy. One exception is in the diagnosis of an autonomous functioning nodule predominantly secreting T3.

\section{$T S H$ receptor antibodies (TRAb)}

TRAb is a general term to define an antibody that binds the TSHR. TRAb can stimulate, block, or be neutral to the TSHR. GH is due to antibodies that stimulate the TSHR. TRAb is useful in confirming the diagnosis of $\mathrm{GH}[5]$.

Preconception, the presence of elevated TRAb is prognostic of risk of relapse of GH or failing ATD cessation [23]. During pregnancy, TRAb crosses the placenta and may induce fetal hyperthyroidism. TRAb levels over 3 times the upper limit of normal are associated with hyperthyroidism in the fetus and newborn [5].

TRAb assays can be divided into two categories: 1) TSH-binding inhibiting Ig (TBI)/thyrotropin binding inhibitory immunoglobulin (TBII) are competition-based assays that detect all TRAb (stimulating, blocking, and neutral) in patients' sera by their ability to compete for binding of the TSHR and 2) Thyroid-stimulating Ig (TSI) is a bioassay that detects cyclic adenosine monophosphate (cAMP) production in cells incubated with patients' sera and measures stimulating TRAb [24]. More recently, bioassays now have the ability to differentiate between stimulating and blocking antibodies [25].

TBII has a $97 \%$ sensitivity and $99 \%$ specificity for $\mathrm{GH}$ [26]. While TBII is unable to differentiate between stimulating or blocking antibodies, in a patient who is thyrotoxic an elevated TBI is due to the presence of stimulating TRAb in the majority of cases.

While thyroid peroxidase antibody (TPO-Ab) positivity has been associated with increased risk for pregnancy loss and premature delivery in euthyroid women, it is a nonspecific marker for autoimmune thyroid disease with no prognostic value for the fetus and newborn in Graves' Disease.

\section{Pregnancy-related complications}

Poor control of thyrotoxicosis is associated with pregnancy loss, pregnancy-induced hypertension, prematurity, low birth weight, intrauterine growth restriction, stillbirth, thyroid storm, and maternal congestive heart failure [27-29]. Women with uncontrolled GH are 9.2 times more likely to have neonates with low birth weight compared to non-GH women. However, if disease is controlled during pregnancy, they are 2.3 times as likely. Mothers with uncontrolled GH are also 16.5 times more likely to undergo preterm delivery and 4.7 times more likely to develop severe preeclampsia compared with women whose GH was controlled [30]. The rate of fetal demise and stillbirth in mothers with poorly controlled GH is $5.6 \%$ [31]. Persistent maternal TBII levels $>5 \mathrm{IU} / \mathrm{L}$ (approximately $3 \times \mathrm{ULN}$ ) in the latter half of pregnancy predicted neonatal hyperthyroidism with $100 \%$ sensitivity and $43 \%$ specificity (Table 2) [32].

\section{Maternal management}

ATDs remain the treatment of choice for $\mathrm{GH}$ during pregnancy. The lowest dose of ATD needed to maintain TT4 1.5 $\times$ the upper limit of the non-pregnant reference range or FT4I at the upper limit of the reference range

Table 2 Risk factors for complications associated with hyperthyroidism in pregnancy

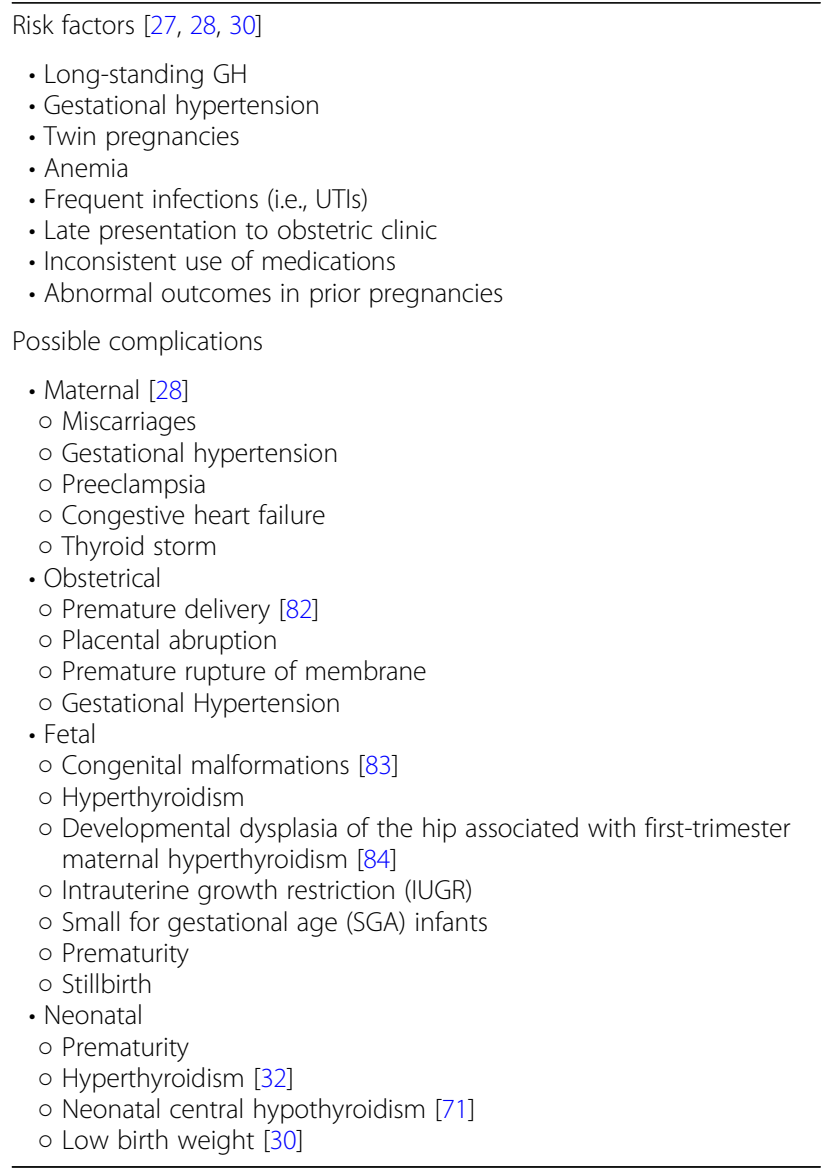


should be used. We have observed that normalization of FT4I can lag behind FT4 during ATD therapy leading to unwarranted larger doses of ATDs [33]. Care must be taken to avoid overtreatment with ATD. TSH may remain suppressed during ATD therapy even when TT4 of FT4I has normalized. The ATD dose should be lowered if TSH becomes detectable [33, 34]. "Block and replace" therapy, which consists of using an ATD in combination with levothyroxine therapy, is not recommended [29].

In the first trimester, PTU can be dosed at $50-150 \mathrm{mg}$ every $8 \mathrm{~h}$ depending on the severity of the patient's symptomatology. When switching from MMI to PTU, a ratio of 1:20 is used (i.e., MMI $15 \mathrm{mg}=300 \mathrm{mg}$ of PTU per day dosed as $100 \mathrm{mg}$ PO every $8 \mathrm{~h}$ ) [2]. After the first trimester, MMI 5-20 mg can be given as a single dose. Occasionally, in very symptomatic patients up to $30-40 \mathrm{mg}$ can be used daily. Propranolol $10-20 \mathrm{mg}$ every $6-8 \mathrm{~h}$ can be used to control hyperadrenergic symptoms and tapered and discontinued as tolerated. Long term treatment with ß-blockers has been associated with poor intrauterine growth, fetal bradycardia, and neonatal hypoglycemia [35]. TSH, FT4/FT4I, or TT4 should be checked every 2-4 weeks as clinically indicated and doses of ATDs titrated based on clinical and biochemical response. ATD may be discontinued in women with mild disease requiring low dose of ATD and mildly elevated TRAb. In $30-40 \%$ of women, ATD may be discontinued after 30-34 weeks of gestation [34]. Fetal hypothyroidism is an indication to decrease or stop ATD.

\section{Measurement of TRAb in pregnancy}

TRAb should be checked in a pregnant woman with a past history of $\mathrm{GH}$ or active $\mathrm{GH}[36,37]$. If TRAb levels are low or undetectable in early pregnancy, no further TRAb testing is recommended [2]. If maternal TRAb is elevated or patient is being treated with ATDs, TRAb should be measured again between weeks $18-22$. In those with levels near 3-4× above upper limit of normal (ULN), TRAb should be checked again during weeks 28-34. Maternal TRAb serum concentration greater than 3 times the upper limit of the reference range in the third trimester is a risk factor for neonatal hyperthyroidism [32, 38-40].

\section{The role of thyroidectomy}

Thyroidectomy in the second trimester is an effective option if a woman is unable to tolerate ATDs, nonconsistent with drug therapy, requiring very high doses of ATDs, has a large goiter, or allergic to ATD. ß-blockade should be used to prepare patients for surgery and continued after surgery. A few days of SSKI or saturated solution of potassium iodide (50-100 mg/day) to help decrease the vascularity of the thyroid gland and control hyperthyroidism can be considered and is safe for the fetus [41].

\section{Thyroid storm (TS) in pregnancy}

TS is a rare complication of uncontrolled GH. Given its rarity, the incidence of TS in pregnancy is not clear. Davis et al. described 1 case in 120,000 deliveries over the span of 11 years at a single institution [27]. TS may occur when a chronically hyperthyroid patient encounters an additional stress or precipitating event (i.e., infection, preeclampsia, labor, surgery, or pregnancy) that leads to decompensation. Patients with TS present with tachycardia, thermic dysregulation, and altered mental status. If not adequately treated, TS can lead to multi-organ failure including congestive heart failure. Biochemical testing reveals suppressed TSH and elevated T4. Patients are best served in the ICU as they may require intubation and IV medications. Treatment entails adequate ATD, betablockade, and supportive care (Table 3).

\section{Anti-thyroid drugs: Complications for mother and fetus}

ATD remains the mainstay treatment of women with GH during pregnancy. $3-5 \%$ of these women experience side effects. An allergic reaction is the most common side effect [42]. More severe side effects such as agranulocytosis $(0.15 \%)$ and liver failure $(<0.1 \%)$ are rare $[43,44]$.

PTU and MMI are equally effective, cross the placenta at comparable rates, and may produce fetal hypothyroidism with or without goiter. Rates of fetal defects have been shown to be similar with both drugs; $2-3 \%$ with PTU and 2-4\% with MMI [45-47]. Notably, this is similar to the overall $3 \%$ rate of major structural or genetic birth defects in the United States [48]. ATD associated defects are most common and severe in those exposed during weeks 6-10 $[7,45,47,49,50]$. PTU has traditionally been preferred over MMI in the first trimester because the birth defects associated with PTU are considered less severe and surgically correctable (Table 4) [51, 52]. Recently, a metaanalysis showed an increased risk of neonatal congenital malformations associated with MMI, but not PTU when compared to no ATD exposure [53]. However, other studies have not shown any difference in rates of congenital malformations between those treated with MMI or PTU and the general population [54].

\section{Fetal and neonatal thyroid function}

The fetal (f) thyroid gland develops between 5 and 6 weeks gestation [55] and starts secreting thyroxine at 10 weeks of gestation [56]. Fetal thyroid hormone (fTH) production is limited until 18-20 weeks of gestation when fTSH receptors begin to function $[57,58]$. fTSH levels will begin to rise until 28 weeks of gestation. fT4 levels will continue to rise until the end of pregnancy [59]. Prior to the onset of $\mathrm{fTH}$ production, the fetus relies on $\mathrm{TH}$ from the mother via transplacental passage [60].

Immediately after birth there is a rise in TSH, T4, and T3. TSH surges and peaks in the first $24 \mathrm{~h}$ of life and 
Table 3 Management of Thyroid Storm [34, 63]

\begin{tabular}{|c|c|}
\hline ATD management (decreases the synthesis and release of T4 and T3) & $\begin{array}{l}\text { - PTU } 100-150 \mathrm{mg} \text { PO every } 8 \mathrm{~h} \text { (PO, NGT) or } \\
\text { - MMl } 20 \mathrm{mg} \text { PO every } 12 \mathrm{~h} \text { (PO, NGT) or } \\
\text { - MMl } 40 \mathrm{mg} \text { in } 200 \mathrm{~cm}^{3} \text { water (Per rectum) }\end{array}$ \\
\hline $\begin{array}{l}\text { Non-selective beta blockade (symptomatic relief) to target: } \\
B_{1}-\text { Heart rate } \\
B_{2}-\text { Vasodilation } \\
B_{3}-\text { Basal metabolic rate and heat production }\end{array}$ & $\begin{array}{l}\text { - Propranolol } 1 \mathrm{mg} \mathrm{IV} \text { bolus followed by } 1 \mathrm{mg} / \mathrm{h} \text { (target heart rate of } \\
\text { 90-100 bpm if adequately hydrated) }\end{array}$ \\
\hline $\mathrm{T} 4$ and $\mathrm{T} 3$ release & $\begin{array}{l}\text { - SSKI (potassium iodide) } 5 \text { drops or Lugol's solution } 10 \text { drops every } 8 \text { h, } 1 \text { h } \\
\text { after MMI (PO, NGT) }\end{array}$ \\
\hline Generation of $\mathrm{T} 3$ & $\begin{array}{l}\text { - Decadron } 4 \mathrm{mg} \text { IVPB every } 6 \mathrm{~h} \\
\text { - PTU at above doses decreases peripheral conversion of T4 to T3 }\end{array}$ \\
\hline Incorporation of T4 and T3 into the nucleus & $\cdot$ - L-carnitine $1-2 \mathrm{~g}$ twice a day $[85]^{\mathrm{a}}$ \\
\hline Fever & $\begin{array}{l}\text { - Aspirin may increase thyroid hormones and acetaminophen can interfere } \\
\text { with steroids. } \\
\text { - Should improve with other treatment modalities. }\end{array}$ \\
\hline Supportive care & $\begin{array}{l}\text { - Antibiotics as infection common precipitating event } \\
\text { - IVF -TS patients are at a fluid deficit. Fluid balance should be net positive. } \\
\text { - Recommend against active cooling as can lead to peripheral vasoconstriction } \\
\text { and hinder release of heat } \\
\text { - Avoid aggressive use of diuretics. Intravascular depletion can lead to } \\
\text { cardiovascular collapse } \\
\text { - Low threshold to intubate }\end{array}$ \\
\hline
\end{tabular}

$P O$ per oral, $N G T$ nasogastric tube, $P R$ per rectum, IVF intravenous fluids

${ }^{\mathrm{a}}$ No studies in pregnant patients

remains elevated for up to 3 to 5 days. T4 and T3 serum concentrations increase up to 6-fold within the first few hours of life, peaking at 24 to $36 \mathrm{~h}$ after birth $[57,59]$.Thyroid function tests gradually decrease to normal levels by 3 to 4 days of age [61].

\section{Monitoring the fetus}

Fetal risks in mothers with GH include hyperthyroidism due to inappropriate transplacental passage of maternal $\mathrm{TRAb}$ and hypothyroidism due to excessive maternal administration of ATD. During routine OB visits, antepartum surveillance should include assessment of fetal heart rate, typically performed with handheld doppler monitor. Fetal tachycardia is concerning for a thyroid etiology. Other causes of tachycardia such as infection, medications (cocaine, terbutaline), obstetric conditions

Table 4 Birth defect associated with ATD

\section{$\mathrm{MMI}$}

- Aplasia cutis

- Choanal atresia

- Esophageal atresia

- Omphalocele

- Urinary tract malformations

- Eye defects

- Ventral septal defects

- Dysmorphic facies

- Athelia

- Developmental delay

PTU

- Pre-auricular sinus/fistula and cysts

- Urinary tract abnormalities in males (placental abruption, fetal bleeding), and fetal tachyarrhythmias should be ruled out [62].

\section{TRA $b$ titers and the fetus}

As discussed previously, maternal serum TRAb titers provide useful prognostic information. TRAbs can cross the placenta and act to stimulate or block fetal thyroid hormone production once the fetal thyroid gland becomes functional [1, 2]. As stated above, persistent maternal TRAb levels greater than 3 times the ULN in the latter half of pregnancy predicted neonatal hyperthyroidism with $100 \%$ sensitivity and $43 \%$ specificity [32].

\section{Indications for fetal ultrasound (FUS)}

Women with a prior fetus or neonate with a thyroid disorder, TRAb greater than 3 times the ULN, fetal tachycardia, and poorly controlled hyperthyroidism should have a FUS. Initial US is generally performed at 18-22 weeks and then every 4 weeks to assess for gestational age, fetal viability, amniotic fluid volume, fetal anatomy, and detection of malformations [2,63].

\section{US findings of hyperthyroidism}

The earliest sonographic sign of fetal thyroid dysfunction is fetal goiter, which appears as a solid neck mass $[56,64]$. $\mathrm{HR}>160 \mathrm{bpm}$ for over $10 \mathrm{~min}$, intrauterine growth restriction, presence of fetal goiter, advanced bone age, or oligo/polyhydramnios can also be seen in fetal hyperthyroidism [65]. Less commonly, fetal thyrotoxicosis can lead to heart failure, fetal hydrops, and fetal demise [63]. 
Fetal goiter can cause fetal, obstetric, and neonatal complications including polyhydramnios secondary to reduced swallowing ability, cervical dystocia, and mechanical obstruction of the fetal airway respectively [58, 66, 67]. Cesarean delivery may be preferred due to high risk of labor dystocia from a deflexed head [68].

\section{Fetal hypothyroidism secondary to ATD drugs}

Fetuses of mothers with GH on ATD can develop hypothyroidism and/or goiter due to overtreatment with ATDs [34]. Signs of hypothyroidism on FUS include fetal goiter, growth restriction, and delayed bone age [63]. ATD dose reduction or discontinuation should restore normal fetal thyroid function and decrease the size of the fetal goiter [56]. Rarely, intra-amniotic levothyroxine injections in conjunction with reduction of ATD dose may be indicated as combination therapy may lead to faster resolution of fetal goiter and recovery from hypothyroidism [67].

In the rare circumstance where the diagnosis remains unclear, cordocentesis remains the method of choice for confirmation of fetal thyroid status [1, 2, 57, 64]. Known as fetal blood sampling, cordocentesis involves US guided placement of a needle into the fetal circulation usually through direct placement into a free loop of umbilical cord or at the cord insertion site. Alternatively, $\mathrm{TH}$ concentrations in the amniotic fluid can be measured $[58,65]$. While less hazardous, amniotic fluid hormone levels have not been validated as a reliable measure of fetal thyroid function [56].

Injection of levothyroxine into the umbilical vein should be restricted to cases of confirmed fetal hypothyroidism and progressive polyhydramnios in spite of repeated intra-amniotic injections [56, 69]. Overall risk of fetal complications associated with cordocentesis and intraamniotic injection is low at $0.5 \%$ to $1 \%$ when performed at experienced centers $[2,57,66]$. The change in size of fetal goiter and extent of polyhydramnios help determine the response to treatment [64]. Repeat cordocentesis may be necessary to monitor therapy [70].

\section{Fetal thyrotoxicosis}

Isolated fetal hyperthyroidism in a euthyroid mother is treated with MMI 10-20 mg daily or larger doses if necessary after the first trimester with adjustment of the dose every few days based on fetal tachycardia and goiter size [34]. The lowest dose necessary to normalize the fetal heart rate (110-160 beats per minute) should be used [1]. Fetal assessment should then be performed every 1-2 weeks or as necessary with evaluation of fetal heart tones with hand-held doppler and US to assess growth, size of fetal thyroid gland, and amniotic fluid index. Care must be taken to prevent inducing fetal hypothyroidism due to excessive administration of ATD.

\section{Neonatal management}

The neonatology team or treating pediatrician should be alerted regarding the mother's diagnosis of thyroid disease before delivery [63]. Maternal use of ATDs during gestation, presence of TRAbs, and degree of control should be communicated directly. Progressive or complex thyroid illness during pregnancy warrants consideration of consultation with a pediatric endocrinologist prior to delivery [2].

Newborns of hyperthyroid mothers should be evaluated soon after birth. Neonates are at risk of hypothyroidism secondary to maternal ATD therapy, central hypothyroidism from untreated mothers via suppression of fetal TSH production that impairs the hypothalamic-pituitary-thyroid maturation $[1,71]$ and hyperthyroidism after the effect of maternal ATDs dissipates [33]. All newborns should be screened for thyroid dysfunction within 2 to 4 days after birth as early postnatal treatment reduces the risk of intellectual impairment [2].

TRAb can remain in the infant's circulation for up to four months after delivery leading to postnatal thyrotoxicosis in 1-5\% of infants of mothers with GH [34]. The diagnosis may be delayed by $48-72 \mathrm{~h}$ due to the transplacental passage of ATD medication [59]. FT4 measurement at birth should be repeated between days 3 and 5 of life and continuously followed if elevated [40]. TRAb positive neonates without biochemical or clinical evidence of thyroid dysfunction should have weekly clinical and laboratory follow up until the TRAb test becomes negative [40].

Some hyperthyroid neonates are first diagnosed at birth. Signs of neonatal thyrotoxicosis include tachycardia, tachypnea, pulmonary arterial hypertension, systemic hypertension and heart failure. They may also be small for gestational age with accelerated bone maturation and craniosynostosis [34, 63]. The recommended treatment regimen for neonatal hyperthyroidism is MMZ $0.5-1 \mathrm{mg} /$ day with addition of propranolol $(2 \mathrm{mg} / \mathrm{kg} / \mathrm{d})$ if severe [2]. PTU is not recommended as a first line treatment due to the high frequency of hepatotoxicity, liver failure and death, particularly in children [72]. Follow up is necessary until the hyperthyroidism resolves which may take months.

In cases of non-transient hypothyroidism, the recommended starting dose of levothyroxine is $10-15 \mathrm{mcg} / \mathrm{kg} /$ day in term neonates. Therapy should be initiated within two weeks of life for optimal outcomes and the infant should be followed for the first three years of life [2]. Most children do well with treatment and higher initial thyroxine dosage combined with shorter time to normalization contribute to improved neurodevelopmental outcome [61].

\section{Maternal post-partum management}

GH mothers taking ATD at time of delivery should continue ATD after delivery even if breastfeeding. Those in 
remission are at risk for developing recurrent $\mathrm{GH} 4$ to 12 months after delivery [73]. Elevated TRAb titers would favor relapse of GH. TSH and FT4 should be checked routinely the first year starting at 6 weeks after delivery.

$\mathrm{GH}$ in the postpartum period needs to be distinguished from postpartum thyrotoxicosis (PPT), a de novo autoimmune thyroid condition that occurs in approximately $5 \%$ of pregnancies in the first year postpartum [74]. PPT classically begins with a transient hyperthyroid phase followed by transient hypothyroidism before a return to euthyroidism. PPT does not require treatment with ATD. High TRAb titers would support relapse of GH. If the diagnosis remains unclear, 123-I RAIA uptake can help distinguish between GH and PPT in a non-breast-feeding woman [75]. If a woman is breastfeeding and a 123-I RAIA study must be done, the mother should discard the breast milk for 3-4 days [2].

\section{Breastfeeding}

Breastfeeding has been shown to be safe in mothers taking ATDs in appropriate doses. MMI and PTU both appear in breast milk in very small concentrations [76-78]. Studies of infants exposed to ATDs in breast milk in doses sufficient to control maternal GH had normal thyroid function and normal intellectual development [79, 80]. MMI is generally preferred in breastfeeding mothers because of hepatotoxicity associated with PTU. Experts recommend using the lowest effective doses possible with maximal doses of MMI $20 \mathrm{mg}$ daily and PTU $300 \mathrm{mg}$ daily $[42,81]$. Doses should be split into 2 to 3 doses and administered after the mother has breastfed.

\section{Conclusions}

The goal in the care of women with GH is the delivery of a euthyroid healthy newborn to a healthy mother. Establishing the diagnosis of $\mathrm{GH}$ can be challenging for the physician. Physical exam, history, and occasionally TRAb levels, can help distinguish GH from GTT, the most common cause of hyperthyroidism in pregnancy. Maintaining euthyroidism throughout pregnancy is key to reducing the risk of maternal, fetal, and newborn complications. ATDs remain the cornerstone of treatment of GH in pregnancy, with the lowest doses needed to maintain TT4 at $1.5 \times$ the upper limit of the non-pregnant reference range or FT4I in the upper limit of the reference range. PTU is preferred in the first trimester. In women with mild GH controlled on low doses of ATD with mildly elevated TRAb levels, ATD may be stopped in the last 48 weeks of pregnancy. Limited course of $\beta$-adrenergic blockers may be used to control symptoms of GH. Surgery in the second trimester may be indicated for women unable to take ATD, uncontrolled on high doses of ATD, or with large goiters. Persistently elevated levels of TRAb $>3 \times$ upper limit of normal is prognostic of fetal thyroid dysfunction and calls for close attention of the fetus and newborn. In the postpartum period, women are at risk for recurrence of GH symptoms and thyroid function tests should be evaluated at 6 weeks.

A multidisciplinary approach involving collaboration between the endocrinologist, maternal-fetal specialist, obstetrician, neonatologist, pediatric endocrinologist, and anesthesiologist is essential to the successful management of these complex patients. The key to a successful pregnancy begins with preconception counseling.

\section{Abbreviations \\ ATDs: antithyroid drugs; CAMP: cyclic adenosine monophosphate; f: fetal; FT3: free triiodothyronine; FT4: free thyroxine; FT4I: FT4 index; FUS: fetal ultrasound; GH: Graves' Hyperthyroidism; GTT: gestational transient thyrotoxicosis; hCG: human chorionic gonadotropin; IUGR : intrauterine growth restriction; IVF: intravenous fluids; LT4: excessive levothyroxine; MMI: methimazole; NGT: nasogastric tube; PO: per oral; PR: per rectum; PTU: propylthiouracil; RAIA: 131-I radioactive iodine ablation; SGA: small for gestational age; TBG: thyroxine-binding globulin; TBI: TSH-binding inhibiting immunoglobulin; TBII: thyrotropin binding inhibitory immunoglobulin; TPO-Ab: Thyroid peroxidase antibody; TRAb: TSH Receptor Antibodies; TS: Thyroid Storm; TSH: Thyroid- stimulating hormone; TSI: Thyroid-stimulating immunoglobulin; TT3: total triiodothyronine; TT4: total thyroxine; ULN: upper limit of normal}

\section{Acknowledgements \\ N/A \\ Funding \\ None.}

Availability of data and materials

Data sharing not applicable to this article as no datasets were generated or analyzed during the current study.

\section{Authors' contributions}

CN and ES performed the literature review and drafted the manuscript. LB and JM provided guidance and edits. All authors read and approved the final manuscript.

\section{Ethics approval and consent to participate \\ $\mathrm{N} / \mathrm{A}$}

\section{Consent for publication}

N/A

Competing interests

The authors declare that they have no competing interests.

\section{Publisher's Note}

Springer Nature remains neutral with regard to jurisdictional claims in published maps and institutional affiliations.

\section{Author details}

${ }^{1}$ Division of Endocrinology, Diabetes, \& Metabolism, Department of Medicine, Keck School of Medicine, University of Southern California, 1540 Alcazar Street, CHP 204, Los Angeles, Ca 90033, USA. ²Division of Maternal Fetal Medicine, Department of Obstetrics and Gynecology, Keck School of Medicine, University of Southern California, 2020 Zonal Avenue, IRD 220, Los Angeles, CA 90033, USA. ${ }^{3}$ Division of Neonatology, Department of Pediatrics, LAC+USC Medical Center, Keck School of Medicine, University of Southern California, Los Angeles, Ca 90033, USA. ${ }^{4}$ Division of Endocrinology, Diabetes \& Metabolism, Department of Medicine and Obstetrics and Gynecology, Keck School of Medicine, University of Southern California, 1540 Alcazar Street CHP 204, Los Angeles, California 90033, USA. 


\section{Received: 15 September 2017 Accepted: 18 February 2018 / Published online: 01 March 2018}

\section{References}

1. Cooper DS, Laurberg P. Hyperthyroidism in pregnancy. Lancet Diabetes Endocrinol. 2013;1:238-49.

2. Alexander EK, Pearce EN, Brent GA, Brown RS, Chen H, Dosiou C, Grobman WA, Laurberg P, Lazarus JH, Mandel SJ, Peeters RP, Sullivan S. 2017 guidelines of the American Thyroid Association for the diagnosis and Management of Thyroid Disease during Pregnancy and the postpartum. Thyroid. 2017;27:315-89.

3. Zimmerman D. Fetal and neonatal hyperthyroidism. Thyroid. 1999;9:727-33.

4. Kautbally S, Alexopoulou O, Daumerie C, Jamar F, Mourad M, Maiter D. Greater efficacy of Total thyroidectomy versus radioiodine therapy on hyperthyroidism and thyroid-stimulating immunoglobulin levels in patients with Graves' disease previously treated with Antithyroid drugs. Eur Thyroid J. 2012;1:122-8.

5. Laurberg P, Wallin G, Tallstedt L, Abraham-Nordling M, Lundell G, Torring O. TSH-receptor autoimmunity in Graves' disease after therapy with anti-thyroid drugs, surgery, or radioiodine: a 5-year prospective randomized study. Eur J Endocrinol. 2008:158:69-75.

6. Banige MEC, Biran V, Desfrere $L$, Champion V, Benachi A, Ville $Y$, Dommergues $\mathrm{M}$, Jarrau PH, Mokhtari M, Boithias C, Brioude F, Mandelbrot L, Ceccaldi PF, Mitanchez D, Polak M, Luton D. Study of the factors leading to fetal and neonatal Dysthyroidism in children of patients with graves disease. Journal of endocrine. Society. 2017;1:751-61.

7. $\quad$ Laurberg P, Andersen SL. Therapy of endocrine disease: antithyroid drug use in early pregnancy and birth defects: time windows of relative safety and high risk? Eur J Endocrinol. 2014;171:R13-20.

8. Casey BM, Dashe JS, Wells CE, McIntire DD, Leveno KJ, Cunningham FG. Subclinical hyperthyroidism and pregnancy outcomes. Obstet Gynecol. 2006;107:337-41.

9. Goldman AM, Mestman JH. Transient non-autoimmune hyperthyroidism of early pregnancy. J Thyroid Res. 2011;2011:142413.

10. Niebyl JR. Clinical practice. Nausea and vomiting in pregnancy. N Engl J Med. 2010:363:1544-50.

11. Grun JP, Meuris S, De Nayer P, Glinoer D. The thyrotrophic role of human chorionic gonadotrophin (hCG) in the early stages of twin (versus single) pregnancies. Clin Endocrinol. 1997;46:719-25.

12. Lip GY, Beevers M, Churchill D, Shaffer LM, Beevers DG. Effect of atenolol on birth weight. Am J Cardiol. 1997;79:1436-8.

13. Nakhai-Pour HR, Rey E, Berard A. Antihypertensive medication use during pregnancy and the risk of major congenital malformations or small-forgestational-age newborns. Birth Defects Res B Dev Reprod Toxicol. 2010;89:147-54

14. Andersen SL, Olsen J, Carle A, Laurberg P. Hyperthyroidism incidence fluctuates widely in and around pregnancy and is at variance with some other autoimmune diseases: a Danish population-based study. J Clin Endocrinol Metab. 2015:100:1164-71.

15. Amino N, Tanizawa O, Mori H, Iwatani Y, Yamada T, Kurachi K, Kumahara Y, Miyai K. Aggravation of thyrotoxicosis in early pregnancy and after delivery in Graves' disease. J Clin Endocrinol Metab. 1982;55:108-12.

16. Weetman AP. Immunity, thyroid function and pregnancy: molecular mechanisms. Nat Rev Endocrinol. 2010;6:311-8.

17. Tagami T, Hagiwara H, Kimura T, Usui T, Shimatsu A, Naruse M. The incidence of gestational hyperthyroidism and postpartum thyroiditis in treated patients with Graves' disease. Thyroid. 2007;17:767-72.

18. Haddow JE, McClain MR, Lambert-Messerlian G, Palomaki GE, Canick JA, Cleary-Goldman J, Malone FD, Porter TF, Nyberg DA, Bernstein P, D'Alton $M E$, First, second trimester evaluation of risk for fetal aneuploidy research $C$. Variability in thyroid-stimulating hormone suppression by human chorionic [corrected] gonadotropin during early pregnancy. J Clin Endocrinol Metab. 2008;93:3341-7.

19. Roti E, Gardini E, Minelli R, Bianconi L, Flisi M. Thyroid function evaluation by different commercially available free thyroid hormone measurement kits in term pregnant women and their newborns. J Endocrinol Investig. 1991;14:1-9.

20. Berta E, Samson L, Lenkey A, Erdei A, Cseke B, Jenei K, Major T, Jakab A, Jenei Z, Paragh G, Nagy EV, Bodor M. Evaluation of the thyroid function of healthy pregnant women by five different hormone assays. Pharmazie. 2010;65:436-9.
21. Lee RH, Spencer CA, Mestman JH, Miller EA, Petrovic I, Braverman LE, Goodwin TM. Free T4 immunoassays are flawed during pregnancy. Am J Obstet Gynecol. 2009;200:260:e261-6.

22. Wilke TJ. Diagnostic value of three methods for assessing free thyroxine in pregnancy. Ann Clin Biochem. 1983;20(Pt 1):60-1.

23. Hesarghatta Shyamasunder A, Abraham P. Measuring TSH receptor antibody to influence treatment choices in Graves' disease. Clin Endocrinol. 2017;86:652-7.

24. Barbesino G, Tomer Y. Clinical review: Clinical utility of TSH receptor antibodies. J Clin Endocrinol Metab. 2013:98:2247-55.

25. Kahaly GJ. Bioassays for TSH receptor antibodies: quo Vadis? Eur Thyroid J. 2015:4:3-5.

26. Tozzoli R, Bagnasco M, Giavarina D, Bizzaro N. TSH receptor autoantibody immunoassay in patients with Graves' disease: improvement of diagnostic accuracy over different generations of methods. Systematic review and meta-analysis. Autoimmun Rev. 2012;12:107-13.

27. Davis LE, Lucas MJ, Hankins GD, Roark ML, Cunningham FG. Thyrotoxicosis complicating pregnancy. Am J Obstet Gynecol. 1989;160:63-70.

28. Mestman JH. Hyperthyroidism in pregnancy. Best Pract Res Clin Endocrinol Metab. 2004;18:267-88.

29. Laurberg P, Bournaud C, Karmisholt J, Orgiazzi J. Management of Graves' hyperthyroidism in pregnancy: focus on both maternal and foetal thyroid function, and caution against surgical thyroidectomy in pregnancy. Eur J Endocrinol. 2009;160:1-8.

30. Millar LK, Wing DA, Leung AS, Koonings PP, Montoro MN, Mestman JH. Low birth weight and preeclampsia in pregnancies complicated by hyperthyroidism. Obstet Gynecol. 1994;84:946-9.

31. Hamburger J. Diagnosis and management of Graves' disease in pregnancy. Thyroid. 1992;2:219-24.

32. Abeillon-du Payrat J, Chikh K, Bossard N, Bretones P, Gaucherand P, Claris O, Charrie A, Raverot V, Orgiazzi J, Borson-Chazot F, Bournaud C. Predictive value of maternal second-generation thyroid-binding inhibitory immunoglobulin assay for neonatal autoimmune hyperthyroidism. Eur J Endocrinol. 2014;171:451-60.

33. Mestman JH. Hyperthyroidism in pregnancy. Curr Opin Endocrinol Diabetes Obes. 2012;19:394-401

34. Patil-Sisodia K, Mestman JH. Graves hyperthyroidism and pregnancy: a clinical update. Endocr Pract. 2010;16:118-29.

35. Rubin PC. Current concepts: Beta-blockers in pregnancy. N Engl J Med. 1981;305:1323-6.

36. Laurberg P, Nygaard B, Glinoer D, Grussendorf M, Orgiazzi J. Guidelines for TSH-receptor antibody measurements in pregnancy: results of an evidencebased symposium organized by the European thyroid association. Eur J Endocrinol. 1998;139:584-6.

37. Mortimer RH, Tyack SA, Galligan JP, Perry-Keene DA, Tan YM. Graves' disease in pregnancy: TSH receptor binding inhibiting immunoglobulins and maternal and neonatal thyroid function. Clin Endocrinol. 1990;32:141-52.

38. Luton D, Le Gac I, Vuillard E, Castanet M, Guibourdenche J, Noel M, Toubert ME, Leger J, Boissinot C, Schlageter MH, Garel C, Tebeka B, Oury JF, Czernichow P, Polak M. Management of Graves' disease during pregnancy: the key role of fetal thyroid gland monitoring. J Clin Endocrinol Metab. 2005:90:6093-8.

39. Peleg D, Cada S, Peleg A, Ben-Ami M. The relationship between maternal serum thyroid-stimulating immunoglobulin and fetal and neonatal thyrotoxicosis. Obstet Gynecol. 2002;99:1040-3.

40. Besancon A, Beltrand J, Le Gac I, Luton D, Polak M. Management of neonates born to women with Graves' disease: a cohort study. Eur Endocrinol. 2014;170:855-62.

41. Momotani N, Hisaoka T, Noh J, Ishikawa N, Ito K. Effects of iodine on thyroid status of fetus versus mother in treatment of Graves' disease complicated by pregnancy. J Clin Endocrinol Metab. 1992;75:738-44.

42. Mandel SJ, Cooper DS. The use of antithyroid drugs in pregnancy and lactation. J Clin Endocrinol Metab. 2001:86:2354-9.

43. Nakamura H, Miyauchi A, Miyawaki N, Imagawa J. Analysis of 754 cases of antithyroid drug-induced agranulocytosis over 30 years in Japan. J Clin Endocrinol Metab. 2013;98:4776-83.

44. Watanabe N, Narimatsu H, Noh JY, Yamaguchi T, Kobayashi K, Kami M, Kunii Y, Mukasa K, Ito K, Ito K. Antithyroid drug-induced hematopoietic damage: a retrospective cohort study of agranulocytosis and pancytopenia involving 50,385 patients with Graves' disease. J Clin Endocrinol Metab. 2012;97:E49-53.

45. Yoshihara A, Noh J, Yamaguchi T, Ohye H, Sato S, Sekiya K, Kosuga Y, Suzuki M, Matsumoto M, Kunii Y, Watanabe N, Mukasa K, Ito K, Ito K. Treatment of 
graves' disease with antithyroid drugs in the first trimester of pregnancy and the prevalence of congenital malformation. J Clin Endocrinol Metab. 2012;97:2396-403.

46. Cooper DS, Rivkees SA. Putting propylthiouracil in perspective. J Clin Endocrinol Metab. 2009;94:1881-2.

47. Andersen SL, Olsen J, Wu CS, Laurberg P. Birth defects after early pregnancy use of antithyroid drugs: a Danish nationwide study. J Clin Endocrinol Metab. 2013;98:4373-81.

48. Hoyert DL, Mathews TJ, Menacker F, Strobino DM, Guyer B. Annual summary of vital statistics: 2004. Pediatrics. 2006;117:168-83.

49. Andersen SL, Olsen J, Laurberg P. Antithyroid drug side effects in the population and in pregnancy. J Clin Endocrinol Metab. 2016;101:1606-14.

50. Clementi M, Di Gianantonio E, Cassina M, Leoncini E, Botto LD, Mastroiacovo P, Group SA-MS. Treatment of hyperthyroidism in pregnancy and birth defects. J Clin Endocrinol Metab. 2010:95:E337-41.

51. Andersen SL, Olsen J, Wu CS, Laurberg P. Severity of birth defects after propylthiouracil exposure in early pregnancy. Thyroid. 2014;24:1533-40.

52. Bahn RS, Burch HS, Cooper DS, Garber JR, Greenlee CM, Klein IL, Laurberg P, McDougall IR, Rivkees SA, Ross D, Sosa JA, Stan MN. The role of Propylthiouracil in the Management of Graves' disease in adults: report of a meeting jointly sponsored by the American Thyroid Association and the Food and Drug Administration. Thyroid. 2009;19:673-4.

53. Song $R$, Lin H, Chen $Y$, Zhang $X$, Feng W. Effects of methimazole and propylthiouracil exposure during pregnancy on the risk of neonatal congenital malformations: a meta-analysis. PLoS One. 2017;12:e0180108.

54. Gianetti E, Russo L, Orlandi F, Chiovato L, Giusti M, Benvenga S, Moleti M, Vermiglio F, Macchia PE, Vitale M, Regalbuto C, Centanni M, Martino E, Vitti $P$, Tonacchera M. Pregnancy outcome in women treated with methimazole or propylthiouracil during pregnancy. J Endocrinol Investig. 2015:38:977-85.

55. Patel J, Landers K, Li H, Mortimer RH, Richard K. Delivery of maternal thyroid hormones to the fetus. Trends Endocrinol Metab. 2011;22:164-70.

56. Polak M, Van Vliet G. Therapeutic approach of fetal thyroid disorders. Horm Res Paediatr. 2010;74:1-5.

57. Fisher DA. Fetal thyroid function: diagnosis and management of fetal thyroid disorders. Clin Obstet Gynecol. 1997;40:16-31.

58. Munoz JL, Kessler AA, Felig P, Curtis J, Evans MI. Sequential amniotic fluid thyroid hormone changes correlate with goiter shrinkage following in utero thyroxine therapy. Fetal Diagn Ther. 2016;39:222-7.

59. Polak M. Human fetal thyroid function. Endocr Dev. 2014;26:17-25.

60. Andersen SL, Olsen J, Laurberg P. Foetal programming by maternal thyroid disease. Clin Endocrinol. 2015;83:751-8.

61. Simpser T, Rapaport R. Update on some aspects of neonatal thyroid disease. J Clin Res Pediatr Endocrinol. 2010;2:95-9.

62. American College of O, Gynecologists. Practice bulletin no. 116: Management of intrapartum fetal heart rate tracings. Obstet Gynecol. 2010;1 16:1232-40.

63. King JR, Lachica R, Lee RH, Montoro M, Mestman J. Diagnosis and Management of Hyperthyroidism in pregnancy: a review. Obstet Gynecol Surv. 2016;71:675-85.

64. Gruner C, Kollert A, Wildt L, Dorr HG, Beinder E, Lang N. Intrauterine treatment of fetal goitrous hypothyroidism controlled by determination of thyroid-stimulating hormone in fetal serum. A case report and review of the literature. Fetal Diagn Ther. 2001;16:47-51.

65. American College of O, Gynecologists. Practice Bulletin No. 148: Thyroid disease in pregnancy. Obstet Gynecol. 2015;125:996-1005.

66. Nachum Z, Rakover Y, Weiner E, Shalev E. Graves' disease in pregnancy: prospective evaluation of a selective invasive treatment protocol. Am J Obstet Gynecol. 2003;189:159-65.

67. Bliddal S, Rasmussen AK, Sundberg K, Brocks V, Feldt-Rasmussen U. Antithyroid drug-induced fetal goitrous hypothyroidism. Nat Rev Endocrinol. 2011;7:396-406.

68. Aubry G, Pontvianne M, Chesnais M, Weingertner AS, Guerra F, Favre R. Prenatal diagnosis of fetal Goitrous hypothyroidism in a Euthyroid mother: a management challenge. J Ultrasound Med. 2017:36(11):2387-92.

69. Davidson KM, Richards DS, Schatz DA, Fisher DA. Successful in utero treatment of fetal goiter and hypothyroidism. N Engl J Med. 1991:324:543-6.

70. Srisupundit K, Sirichotiyakul S, Tongprasert F, Luewan S, Tongsong T. Fetal therapy in fetal thyrotoxicosis: a case report. Fetal Diagn Ther. 2008;23:114-6.

71. Kempers MJ, van Tijn DA, van Trotsenburg AS, de Vijlder JJ, Wiedijk BM, Vulsma T. Central congenital hypothyroidism due to gestational hyperthyroidism: detection where prevention failed. J Clin Endocrinol Metab. 2003:88:5851-7.
72. Rivkees SA, Mattison DR. Propylthiouracil (PTU) Hepatoxicity in children and recommendations for discontinuation of use. Int J Pediatr Endocrinol. 2009;2009:132041.

73. Rotondi M, Cappelli C, Pirali B, Pirola I, Magri F, Fonte R, Castellano M, Rosei EA, Chiovato $L$. The effect of pregnancy on subsequent relapse from Graves' disease after a successful course of antithyroid drug therapy. J Clin Endocrinol Metab. 2008:93:3985-8.

74. Stagnaro-Green A. Approach to the patient with postpartum thyroiditis. J Clin Endocrinol Metab. 2012:97:334-42.

75. Gorman CA. Radioiodine and pregnancy. Thyroid. 1999;9:721-6.

76. Kampmann JP, Johansen K, Hansen JM, Helweg J. Propylthiouracil in human milk. Revision of a dogma. Lancet. 1980;1:736-7.

77. Johansen K, Andersen AN, Kampmann JP, Molholm Hansen JM, Mortensen HB. Excretion of methimazole in human milk. Eur J Clin Pharmacol. 1982;23:339-41.

78. Cooper DS, Bode HH, Nath B, Saxe V, Maloof F, Ridgway EC. Methimazole pharmacology in man: studies using a newly developed radioimmunoassay for methimazole. J Clin Endocrinol Metab. 1984:58:473-9.

79. Cooper DS. Antithyroid drugs. N Engl J Med. 2005;352:905-17.

80. Eisenstein Z, Weiss M, Katz Y, Bank H. Intellectual capacity of subjects exposed to methimazole or propylthiouracil in utero. Eur J Pediatr. 1992;151:558-9.

81. Karras S, Tzotzas T, Kaltsas T, Krassas GE. Pharmacological treatment of hyperthyroidism during lactation: review of the literature and novel data. Pediatr Endocrinol Rev. 2010;8:25-33.

82. Lo JC, Rivkees SA, Chandra M, Gonzalez JR, Korelitz JJ, Kuzniewicz MW. Gestational thyrotoxicosis, antithyroid drug use and neonatal outcomes within an integrated healthcare delivery system. Thyroid. 2015;25:698-705.

83. Momotani N, Ito K, Hamada N, Ban Y, Nishikawa Y, Mimura T. Maternal hyperthyroidism and congenital malformation in the offspring. Clin Endocrinol. 1984;20:695-700

84. Ishikawa N. The relationship between neonatal developmental dysplasia of the hip and maternal hyperthyroidism. J Pediatr Orthop. 2008;28:432-4.

85. Benvenga $S$, Amato A, Calvani M, Trimarchi F. Effects of carnitine on thyroid hormone action. Ann N Y Acad Sci. 2004:1033:158-67.

\section{Submit your next manuscript to BioMed Central and we will help you at every step:}

- We accept pre-submission inquiries

- Our selector tool helps you to find the most relevant journal

- We provide round the clock customer support

- Convenient online submission

- Thorough peer review

- Inclusion in PubMed and all major indexing services

- Maximum visibility for your research

Submit your manuscript at www.biomedcentral.com/submit
) Biomed Central 